\title{
Los museos de arte: Agentes activos para la equidad social. Proyectos para personas con necesidades específicas de apoyos
}

\author{
Mar MORÓN ${ }^{1}$ \\ mar.moron@uab.cat
}

Enviado: $15 / 03 / 2011$

Aceptado: 12/10/2011

\section{RESUMEN}

Los museos de arte se han transformado en lugares de formación, de experimentación e investigación, de generación de pensamiento y conocimiento, de creación artística y de intercambio para todas las personas que constituimos la sociedad. El museo se hace accesible a todo tipo de público con la incorporación de los recursos que sean necesarios. A lo largo del texto se presentan tres proyectos realizados por el Departament d'Educació del Museu Nacional d'Art de Catalunya para personas con necesidades específicas de apoyos y un taller inclusivo.

Las características de estos proyectos accesibles enumeran y destacan nuevas funciones y potencialidades de estos espacios museísticos que se convierten en agentes activos para fomentar la equidad social $^{2}$.

Palabras clave: museos de arte, personas con necesidades específicas de apoyos, accesibilidad, equidad social

\section{Referencia normalizada}

MORÓN, M.(2011). "Los museos de arte Agentes activos para la equidad social Proyectos para personas con necesidades específicas de apoyos.". En Arteterapia: Papeles de arteterapia y educación artística para la inclusión social Vol.: 6. Páginas 253-268 Madrid. Servicios de publicaciones UCM.

\section{SUMARIO}

Introducción. El museo, un espacio de formación en educación artística para educadores, maestros y profesores. Los educadores del Departamento de Educación fuera del museo. El museo, un espacio de contemplación, observación y generación de conocimiento. El museo, un espacio de investigación, experimentación y expresión. El museo, un espacio para compartir, un ámbito de encuentro con uno mismo y con los otros, de interacción entre contexto, personas y materiales. El museo, un espacio generador de propuestas para la práctica del arte y un lugar de creación de pensamiento y de ejecución: de pensar y de hacer. El museo, un espacio para exhibir los procesos de creación y los resultados. Conclusión. Referencias bibliográficas.

${ }^{1}$ Profesora de Didàctica de l'Expressió Plàstica a la Facultat de Ciències de l'Educació de la Universitat Autònoma de Barcelona. Colaboradora en el Programa Museu Espai Comú d'Integració del Departament d'Educació del Museu Nacional d'Art de Catalunya (MNAC).

${ }^{2}$ Destacamos el concepto de equidad por su connotación de justicia e igualdad social con responsabilidad y valoración de cada individualidad. 


\title{
The art's museums: Active agents for the social equity. Projects for persons with specific needs of educational supports
}

\begin{abstract}
The museums of art have transformed in places of formation, of experimentation and investigation, of generation of thought and knowledge, of artistic creation and of exchange for all the persons that we constitute the company. The museum becomes accessible to all kinds of public by the incorporation of the resources that are necessary. Along the text there are described three projects realized by the Departament d'Educació of the Museu Nacional d'Art of Catalonia for persons with specific needs of supports and an inclusive workshop.

The characteristics of these accessible projects enumerate and emphasize new functions of these spaces of museums that turn into active agents to promote the social equity.
\end{abstract}

Keywords: museums of art, persons with specific needs of supports, accessibility, social equity

\section{CONTENTS}

Introduction. The museum, a space of formation in artistic education for educators and teachers. The educators of the Department of Education out of the museum. The museum, a space of contemplation, observation and generation of knowledge. The museum, a space of investigation, experimentation and expression. The museum, a space to share. An area of meeting with one itself and with others, of constant interaction between context, persons and materials. The museum, a generating space of offers for the practice of the art and a place of creation of thought and of execution: of thinking and of doing. The museum, a space to exhibit the processes of creation and the results. Conclusion. Bibliographical references and web pages.

\section{INTRODUCCIÓN}

La idea de museo como lugar de exposición y contemplación de obras de arte exclusivo para un colectivo selecto de intelectuales y entendidos en arte ha quedado caduca. Los museos se han convertido en espacios también de observación, de investigación, de experimentación, de exhibición de procesos y resultados de creaciones artísticas; en lugares en los que generar pensamiento y compartir conocimiento, en los que se originan estrategias para acercarse al arte y a la cultura de un modo enriquecedor y favorecedor de un desarrollo íntegro de todas las personas.

Uno de los retos actuales de los museos es dar accesibilidad a todos los colectivos que formamos parte de la sociedad, desde los más expertos en la materia hasta aquellos que necesitan de unos apoyos específicos para el acceso a la cultura. Nos estamos refiriendo al concepto de accesibilidad universal que se aplica a que todas las personas puedan ser beneficiarias de lo que tiene de específico el arte. Como bien nos comenta Eisner (2008) al exponer los dos tipos de justificación ${ }^{3}$ de la educación artística, los investigadores esencialistas destacan lo que el arte tiene de propio,

\footnotetext{
${ }^{3}$ Según Eisner (2005) existen dos tipos de justificación para la educación artística: en primer lugar, una justificación contextualista, en la cual se analizan las características del contexto (entorno y estudiantes) para conformar los objetivos que tendrán como finalidad última la mejora de la sociedad; y en segundo lugar, la justificación esencialista.
} 
aquella contribución a la experiencia y al conocimiento que sólo esta disciplina puede ofrecer. Los pensadores de esa corriente consideran que el arte es un aspecto único de la cultura y de la experiencia humana y que su contribución más valiosa consiste en aportar sus valores implícitos y sus características específicas.

Una obra de arte es una forma expresiva que percibimos a través de los sentidos y de la imaginación y que expresa sentimientos humanos.

Langer $^{4}$, cit. en Eisner, 2005: 66

El arte hace referencia también al simbolismo lo que implica utilizar el arte para poder expresar aquellos significados que sólo él puede expresar, quizá de una forma no discursiva, pero que conecta con la parte más íntima del creador para comunicarla al espectador. De este modo, el arte proporciona un conocimiento del mundo, haciendo una aportación única a la experiencia individual. Las artes plásticas y visuales remiten a un aspecto de la conciencia humana que ningún otro campo aborda: la contemplación estética de la forma visual.

Las obras de arte nos transportan también al mundo de la fantasía y del sueño. Nos hacen revivir viejas imágenes y nos transportan con las alas de la imagen visual al mundo fantástico del sueño. Estas obras nos ayudan a participar de nuevo en los momentos mágicos de la mente y a revelar ideas y sentimientos escondidos en sus entresijos.

Eisner, 2005: 10

Así, se hace imprescindible poder incluir a todos los colectivos en estas experiencias tan específicas que nos ofrece el arte entre otras muchas que iremos analizando a lo largo de este texto.

Las personas con diversidad funcional $1^{5}$, a lo largo de este siglo, se han visto inmersos en un recorrido que va desde etapas exclusivas en las que sólo se intentaba dar respuesta a sus necesidades básicas de manera benéfico-asistencial, pasando por etapas médicas, etapas que reeducaban aquello que todavía no se había logrado educar, hasta nuestros días, en los que se prioriza un modelo social de normalizar y

\footnotetext{
${ }^{4}$ Susanne Langer, filósofa estadounidense seguidora de Ernst Cassirer, argumenta de forma incluso más rotunda el carácter único del arte. Afirma que existen dos modos básicos de conocimiento a través de los cuales el individuo llega a conocer el mundo: el modo discursivo, basado en el método científico y la lógica, y el modo no discursivo, el cual se fundamenta en cómo las artes aportan intuitivamente valores a este segundo modo de conocer. Para Langer, el arte es un símbolo constructo que presenta a nuestra percepción el conocimiento de las formas de sentimiento de un artista.

${ }^{5}$ Utilizaremos los términos personas con diversidad funcional o personas con necesidades específicas de apoyos para designar a las personas con discapacidad intelectual y/o motriz por parecernos más normalizadoras. Prescindiremos del concepto "discapacidad" por sus connotaciones negativas y su referencia a las limitaciones. Preferimos hacer hincapié como educadores en las capacidades de todas las personas, en lo que son capaces de hacer, en las características múltiples de cada individuo y en la normalización de su funcionalidad gracias a los recursos de su entorno.
} 
prosperar con las diferencias y que no incumbe únicamente al individuo sino a la sociedad como responsable de proporcionar aquellos elementos que estas personas necesitan para el acceso a una buena calidad de vida. De esta manera, una persona con discapacidad no es una persona únicamente con limitaciones sino una persona con unas características personales que hacen que necesite de una serie de recursos específicos para su desarrollo cognitivo, personal y social. La utilización de más o menos apoyos estará condicionada por la interacción que establezca la persona con discapacidad y su entorno, en este caso el museo, para facilitar su desarrollo como persona. La OMS (Bradley, 1995 en OMS; en Shalock, 1999) define la discapacidad como resultado de la interacción entre las limitaciones de las personas y las variables ambientales que influyen en el desarrollo de éstas: el entorno, las situaciones sociales y las necesidades específicas. La discapacidad no está fijada, es fluida, continua y cambiante, dependiendo de las restricciones funcionales del individuo y de las ayudas disponibles en el entorno personal y social. Intervenir o proveer de servicios que se centren en la conducta adaptativa del individuo es una forma de reducir las limitaciones funcionales y por tanto, la discapacidad de la persona ${ }^{6}$. Una meta no fácil de alcanzar pero que favorecidos por las leyes inclusivas actuales, las nuevas políticas educativas y estrategias de enseñanza-aprendizaje (entre ellas el uso de las TIC y las TAC), y la sensibilización de las personas en la riqueza de formar parte de una sociedad equitativa y solidaria, se puede conseguir.

Este texto que presentamos intenta exponer unas prácticas museísticas que facilitan la accesibilidad al arte y a la cultura de uno de estos colectivos: las personas con diversidad funcional, concretamente con discapacidad intelectual. Estas personas presentan capacidades y también, limitaciones significativas tanto en el funcionamiento intelectual (considerando la inteligencia desde un modelo multidimensional: inteligencias múltiples) como en la conducta adaptativa que se manifiesta en las habilidades adaptativas: conceptuales, sociales y prácticas (AAMR $\left.{ }^{7}, 2006\right)$. El investigador Shalock (2001) fusiona estos dos conceptos en uno único, la competencia personal: competencia física, inteligencia conceptual, inteligencia práctica, inteligencia social y competencia emocional.

\footnotetext{
${ }^{6}$ Recuerdo el primer proyecto que realizamos en el MNAC con personas con necesidades específicas de apoyos en el que participaron 40 personas con discapacidad intelectual y motriz. La mayoría de estas personas tenían movilidad reducida o se desplazaban con silla de ruedas. Para acceder al museo hay unos cuantos escalones que han solventado con una plataforma individual que significa 5 minutos por persona para subir 4 escalones. Estas personas se hubieran sentido totalmente diferentes si en este proceso de espera hubieran visto como las otras personas pueden tardar únicamente 3 segundos en subir esos escalones y ellos deberían esperar 5 minutos por las 20 personas. Pudimos hacer que estas personas no se sintieran tan diferentes utilizando el montacargas del museo, en el que transportan las obras de arte y en el que cabían 10 personas por viaje: se habían reducido las limitaciones de estas personas con los recursos que el museo había puesto a su disposición y permitió el acceso y desplazamiento rápido por todas las salas y otros emplazamientos del museu.

${ }^{7}$ AAMR (2006) El retard mental. Definició, classificació i sistemes de suport. Barcelona, Eumo Editorial
} 
Conocedores de las características de estas personas (tener presente que no se dan en todos los sujetos y que además, cada una de estas personas tiene su propia idiosincrasia y factores externos que influirán en su evolución) se ofrecen desde el museo una serie de proyectos que intentan a través de la proximidad al arte potenciar la competencia personal en estas personas. Con el objetivo de ampliar sus conocimientos y experiencias para que puedan desarrollar unas habilidades cognitivas, personales y sociales que mejoren su ser y estar en la vida.

Algunos de los Departamentos de Educación de los museos han iniciado esta aventura de acercar el arte a las personas con diversidad funcional, entre ellos el Departament d'Educació del Museu Nacional d'Art de Catalunya ${ }^{8}$ que desde 1998 incluye en su programación proyectos para estas personas y también, para personas con enfermedad mental.

Estos proyectos han sido diseñados exclusivamente para este tipo de colectivos, analizando sus características, intereses y necesidades, y como principal objetivo utilizar el contacto con las obras de arte para, como hemos comentado anteriormente, desarrollar esas habilidades cognitivas y personales que les serán indispensables para su normalización e inclusión en la sociedad. Añadimos unas palabras de Alexandre Jollien ${ }^{9}$ en las que como persona con discapacidad nos relata la necesidad de proximidad afectiva hacia estas personas para beneficio de todos:

\begin{abstract}
ALEXANDRE
El enemigo a combatir después de mi estancia en el centro fue la falta de confianza en mí mismo y la incomprensión. ¡Necesitaba no solamente aceptar sino también asumir mi anormalidad! Nunca sería del todo como los demás, nunca sería normal. Necesitaba también hallar la fuerza para comprender lo incomprensible, para perdonar lo imperdonable, y al mismo tiempo, de ser posible, hacerlo con alegría.
\end{abstract}

Jollien, 2001: 110

Analizamos en estas páginas algunas de las estrategias que hacen posible estos proyectos accesibles ${ }^{10} \mathrm{y}$ de qué manera se está transitando hacia propuestas para todo tipo de personas, como el taller de Color $^{11}$.

8 El Departament d'Educació del MNAC está formado por una persona responsable del Departamento e historiadora del Arte y dos técnicas: una maestro e historiadora del arte y maestro y la segunda, licenciada en Bellas Artes.

${ }^{9}$ Alexander Jollien, filósofo y escritor suizo con diversidad funcional, parálisis cerebral.

${ }^{10}$ Señalar como diseñadora y conductora de estos proyectos para personas con diversidad funcional, mi formación teórico-práctica es maestra especialista en pedagogía terapéutica y licenciada en Bellas Artes; y también, formación e investigación en el campo del arte: creación artística personal.

${ }^{11}$ El proyecto Color: un taller inclusiu se realizó en el MNAC en el 2009. En él participaron 25 adultos de los cuales cinco tenían diversidad funcional, en concreto, la Síndrome de Down. 


\section{EL MUSEO, UN ESPACIO DE FORMACIÓN EN EDUCACIÓN ARTÍSTI- CA PARA EDUCADORES, MAESTROS Y PROFESORES}

Una vez diseñado el proyecto ${ }^{12}$ de intervención educativa e informados de las características generales en relación a la competencia personal de estas personas con diversidad funcional, necesitábamos la colaboración de los educadores para adaptar el proyecto a las características específicas de cada persona, del centro y de las dinámicas del grupo. Para ello se organizó desde el Departament d'Educació del MNAC una jornada de formación para todos los educadores de los centros participantes. El objetivo era compartir las propuestas y acabar de adaptarlos a la especificidad de cada usuario (así nombran a las personas que forman parte de los centros ocupacionales) y del centro. La manera de llevarlo a cabo fue una inmersión en el proyecto a partir de la realización de todas las actividades por parte de los educadores, desde la visita a las salas, los talleres de creación artística, hasta la puesta en común final.

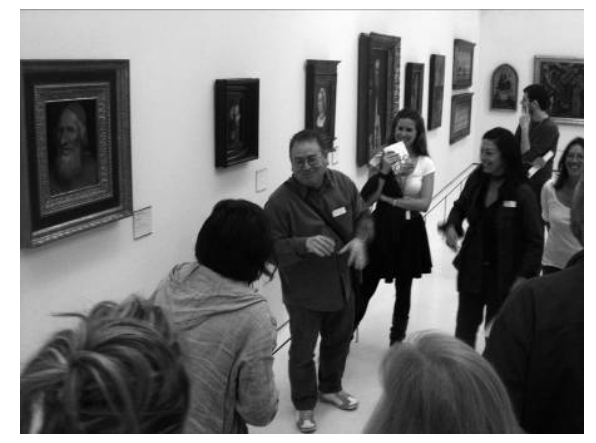

Fig. 1. Fotografía 2. Salas de Art Modern del MNAC. Jornada de formación para los educadores de los centros. Realizando una de las actividades del proyecto Retrats

Con esta jornada se intenta también conseguir una colaboración, implicación y valoración por parte de todos los educadores en las actividades del proyecto y conseguir uno de los objetivos generales:

Acercarlos al arte desde la observación/percepción, la conceptualización y la creación artística.

\footnotetext{
12 Dentro del Programa Museu Espai Comú d'Integració del Departament d'Educació del MNAC he diseñado y conducido 4 proyectos, los que se hace referencia a lo largo de este texto: Natures Mortes, 2007; La ciutat: un lloc per viure, 2008; Retrats, 2009 y Color: un taller inclusiu, 2009. En paralelo a estos proyectos se han realizado otros para personas con enfermedad mental, diseñados y conducidos por Fina Alert.
} 


\section{LOS EDUCADORES DEL DEPARTAMENTO DE EDUCACIÓN FUERA DEL MUSEO}

Se inicia el proyecto con una primera actividad que es conducida por los educadores del museo en el centro educativo o taller ocupacional participante. Con esta estrategia educativa se intenta conseguir una proximidad afectivo-emocional entre los participantes del museo y del centro que facilitará la adaptación de los usuarios al nuevo espacio y a los nuevos educadores ${ }^{13}$, y también una aproximación al tema que se prolongará a lo largo de dos sesiones más como mínimo: la visita y taller de creación en el museo y las actividades de conclusión en sus respectivos centros.

Previamente a esta visita, se envía información sobre el museo, sobre la exposición (catálogo), que es el fundamento de la propuesta, y el proyecto educativo a cada centro. La intención es facilitar a los educadores de los centros poder realizar una primera actividad de contacto, una evaluación inicial de lo que saben y conocen sobre el tema elegido. Este primer acercamiento al contenido del proyecto servirá a su vez de preparación y motivación para las siguientes actividades que se proponen llevar a cabo en el museo. También se abre la oportunidad de realizar una investigación más exhaustiva sobre el tema si así lo consideran los usuarios y/o educadores de los centros ${ }^{14}$.

La estructura de la sesión se divide en varias partes: presentación de todos los participantes de la actividad, la explicación de la propuesta a realizar, la observación de las reproducciones de las obras de arte que se verán en el museo, diálogo entre las obras y los participantes en las que el educador del museo realiza el rol de moderador, y por último, un inicio de la actividad de creación artística que se proseguirá en los talleres del museo después de la visita a las salas y de observar/contemplar las obras en directo.

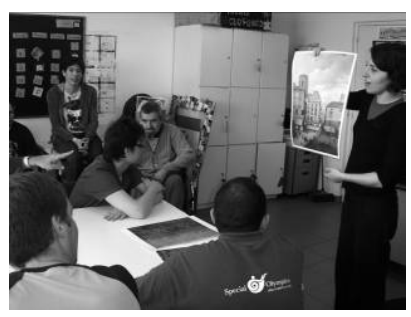

Fig. 2. Sala de trabajo del TEB Estació

de Barcelona (taller ocupacional).

Presentación del proyecto La ciutat: un

lloc per viure por las educadoras del

MNAC.

${ }^{13}$ Cuando llegaban al museo para realizar la segunda actividad, rápidamente preguntaban por las educadoras que los habían acompañado durante la primera actividad en el centro. Eran sus referentes emocionales, necesarios para darles seguridad, confianza y tranquilidad en el nuevo espacio y ante las nuevas actividades.

${ }^{14}$ En el proyecto de La ciutat: un lloc per viure, los usuarios y educadores del centro ASPACE Poblenou buscaron fotografíes de su barrio de la época de las pinturas que se iban a trabajar, para conocer también como era el Poblenou a principios del siglo XX y poder compararlo con el actual. Podemos afirmar por nuestra experiencia que cuanto más cercano sea el tema a tratar a la cotidianidad de estas personas, mayor será su implicación. 
Esta primera sesión en el proyecto de Natures Mortes consistió en analizar las reproducciones de las obras y realizar una lista de los elementos que aparecían, básicamente frutas, entre todos los usuarios. Se les explicó que los pintores de bodegones partían de un modelo real para observarlo y poder pintarlo. De esta manera, se les hizo la propuesta de poder realizar ellos un modelo real para posteriormente, ya en el museo, después de observar las obras en directo y sus características, poder pintarlo. Esta lista que se realizaba entre todos podía ser con lenguaje escrito o con imágenes: dibujos, recortes de revistas, etc. ${ }^{15}$ Su objetivo era poder comprarlas en la tienda y poder realizar los modelos de bodegones individualmente. La actividad concluyó con la compra de frutas en el mercado y la realización de la fotografía de cada modelo.

Durante el proyecto de La ciutat: un lloc per viure, después de analizar las copias de las obras que representaban la Barcelona de principios del siglo XX, salimos por la ciudad a hacer fotografías de los elementos de la ciudad que nos gustaban para construir después en el museo: la maqueta de nuestra ciudad ideal. ${ }^{16}$

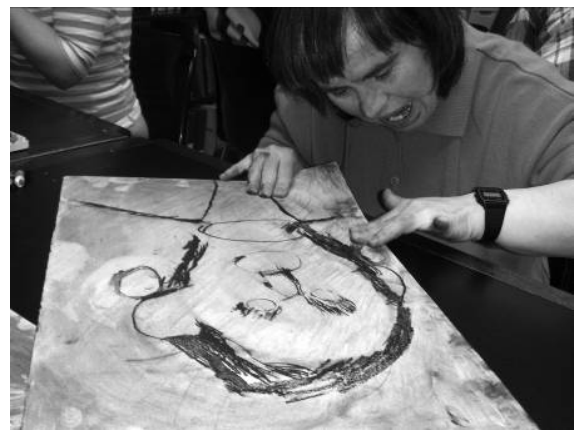

Fig. 3. Sala de trabajo de la Fundació Síndrome de Down de Barcelona. Presentación del proyecto Retrats por las educadoras del MNAC. Realizando una de las actividades propuestas.

\section{EL MUSEO, UN ESPACIO DE CONTEMPLACIÓN, OBSERVACIÓN Y GENERACIÓN DE CONOCIMIENTO}

El arte es emoción, así que predecir lo que pasaría con la contemplación de las obras era casi imposible: pudo ser desde una observación silenciosa hasta originar pensamientos que conectan con la parte más íntima del espectador. El educador del mu-

\footnotetext{
${ }^{15}$ Algunas de estas personas con diversidad funcional utilizan Sistemas de Comunicación Aumentativos para su comunicación, basados en pictogramas o imágenes como son el sistema SPC o el Bliss; entienden con más facilidad la imagen que la palabra.

${ }^{16}$ Recordamos a una persona con movilidad reducida que iba haciendo fotografías de todos los tipos de bancos que encontraba por la ciudad, y a mi pregunta sobre por qué hacía tantas fotografías a los bancos me respondió que él cuando caminaba se cansaba muy rápido y necesitaba que en su recorrido por la ciudad hubieran muchos bancos para descansar. También, el centro ASPACE Badalona prefirió hacer fotografías en una zona nueva de Barcelona que en su ciudad Badalona, en la que no podían moverse autónomamente al tener numerosas barreras arquitectónicas: falta de rampas, aceras estrechas, socavones, transporte público no adaptado, etc.
} 
seo, como ya hemos comentado anteriormente, es el moderador de la comunicación que se establece entre la obra y el espectador; y generador en algunos momentos de elementos que potenciaban el diálogo y el acercamiento entre ambas partes (Modelo Visual Thinking Strategies ${ }^{17}$ ). Las obras en directo funcionan como impulso para establecer este coloquio que consigue la construcción de conocimientos nuevos por parte del espectador, sobre sí mismo y sobre lo que allí está representado ${ }^{18}$.

En el proyecto Retrats, al llegar a las salas del museo se les ofrecían unas reproducciones de obras en las que habían desaparecido los personajes, únicamente con la silueta debían adivinar posibles características de la persona oculta y de la obra de que se trataba; a partir de su encuentro, se les proponía la invención de la historia de ese personaje ${ }^{19}$.

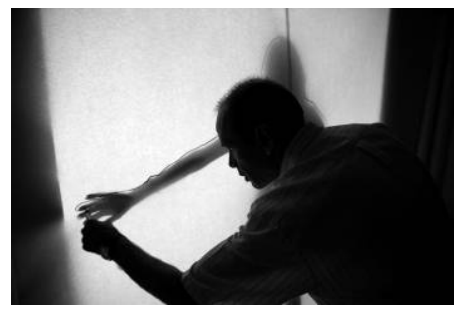

Fig. 4. Taller del MNAC. Realizando

una de las propuestas del proyecto

Retrats

\section{EL MUSEO, UN ESPACIO DE INVESTIGACIÓN, EXPERIMENTACIÓN Y EXPRESIÓN}

La creación artística se convierte en un canal mediante el cual poder expresar y poder sobrepasar aquellos límites que quizás en otras actividades de la vida no se permiten; un canal para dar salida a aquellos sentimientos y emociones profundos que no se pueden expresar por medio de ningún otro lenguaje. Y es esto lo que el arte tiene de especial y de único como comentan los profesionales esencialistas del área de educación artística. Como argumenta el artista Henri Matisse (en Essers, 2002) la creación artística sirve para que la persona creadora exprese sus visiones interiores. Proporciona un espacio de libertad que generalmente es difícil de encontrar en otros momentos.

${ }^{17}$ Este modelo de educación artística fue desarrollado en el MOMA (Museum of Modern Art) de New York por Abigal House y Philip Yenawine, en 1991. Uno de los objetivos del VTS es la creación de pensamiento y el desarrollo de habilidades comunicativas a través del arte.

${ }^{18}$ Recordamos como ante la obra de Joan Colom, L'estació de França, 1911, hubieron varios grupos que se interesaron sobre el funcionamiento del tren de vapor y más tarde, en su centro, hicieron un trabajo de investigación sobre el tema. Como cuando una de las personas, al ver representada una estufa de leña, nos explicó como pasaba las tardes de invierno en casa de su abuela.

${ }^{19}$ En una de las siluetas se adivinaba un lazo en la cabeza del personaje, rápidamente pensaron que se trataba de una mujer, al descubrir que era un hombre se originó un debate sobre la posible homosexualidad de ese hombre y lo que eso significaba. 
El objetivo de la pintura no es representar acontecimientos de la Historia; éstos ya están en los libros. Tenemos una noción más elevada de la pintura. Sirve para que el artista exprese sus visiones interiores.

Matisse, cit. en Essers, 2002: 60

Se considera que en el proceso de creación artística la idea inicial se va transformando por deseo del creador, preferiblemente sin intervención externa. La obra se vuelve parte del creador, son sus ideas, sus intereses, sus inquietudes, etc. que saca al exterior en una pieza/objeto que enseña y muestra al resto de los participantes. El resultado es una representación de los pensamientos del creador. Desde el mundo de la EA autores como Lowenfeld (en Eisner, 2004) considera la actividad creativa como escape emocional que conlleva a que la persona creadora gane en libertad y flexibilidad, como resultado de la descarga de tensiones innecesarias y facilita el que pueda sobrellevar situaciones nuevas sin problemas, adaptándose fácilmente a ellas. Al igual que las producciones de los artistas del movimiento expresionista abstracto que aparecen tras el dolor y la incomprensión que supuso la segunda guerra mundial, las obras de los participantes también sirven como objeto canalizador de emociones: la rabia, emociones que surgen de relaciones personales, dolor, etc. A través de las obras han podido regular sus emociones de una manera constructiva. Contribuye a ello como dice Eisner (2004) el hecho de que el enseñante de arte haya vivido el proceso de creación de manera personal; que se reconozca en el proceso de creación de los participantes: con sus inseguridades, placeres, retos y sorpresas.

La confianza entre todos los participantes es esencial en el proceso de creación artística, no deben sentirse coaccionados ni analizados ni evaluados. Los usuarios son capaces de confiar plenamente en el educador, actitud que facilita el logro de sus objetivos/propuestas y que podrán generalizar en otras relaciones interpersonales. Esta confianza es la base de numerosas experiencias positivas. Son tomados en serio y se les reconoce como únicos. Piden al educador confianza para lograr también la alegría de tener confianza en sí mismos, para creer en sus fuerzas y capacidades, para confiar en el grupo como un todo, en donde cada uno de los participantes es especial. En definitiva, se da libertad y seguridad a los participantes para que sean capaces de controlar su propio desarrollo.

El proceso de creación artística, siguiendo a Eisner (2004), incita a las personas a pensar sobre las posibilidades y limites de los materiales disponibles. A medida que esos pensamientos maduran en base a un reconocimiento más profundo y detallado de tales materiales y el inicio de su manipulación, se genera un conjunto de ideas, un rico universo simbólico creativo lleno de variantes y matices sobre lo que se puede hacer o no. Si además las personas disponen de capacidad técnica para hacer realidad esas ideas, se origina la creación. De este modo se produce una estrecha vinculación entre el pensar y el hacer, como no sucede en otras disciplinas y que permite la retroacción: no sólo se llevan a la práctica las ideas propias, sino que de la práctica propia surgen nuevas ideas. 
En efecto, el taller de creación se convierte en un descubrimiento constante de materiales que motiva a los participantes a emprender una aventura de investigación de sus características y posibilidades y también de las técnicas aplicables a ellos. Incluso entienden la simbolización de los materiales asociando formas y nuevos significados: asociaciones simbólicas de forma-significado ${ }^{20}$.

Durante el proceso de creación, la primera idea del pensamiento creador se va enriqueciendo con un devenir de pensamientos enlazados que van generando la construcción de la obra final. La representación se convierte en un juego simbólico de elementos que irán configurando significados nuevos al ponerse en contacto unos con otros a decisión del propio creador. Así, como dice Eisner (2004), la representación desempeña una función cognitiva en la que varios tipos de pensamiento se ponen en acción: pensamiento asociativo, convergente y divergente; pensamiento causal y consecuencial. La materialidad de la representación hace posible entablar un diálogo con ella. Si se trabajara únicamente con ideas todo sería etéreo y fácil de subjetivizar, la materia permanece y permite una interrelación entre la obra y el creador; así como entre la obra y el espectador.

En todo momento, se intenta que cada proceso de creación y resultado sea único, pensado y decidido por el participante. De esta manera cada uno se va haciendo consciente de su individualidad y de su ser, único y diferente al resto. Van conociendo sus capacidades y limitaciones desde la práctica, cosa que ayuda a la construcción de su propia identidad dentro del grupo, a un autoconocimiento en paralelo al conocimiento de los otros.

En las artes se valora más la individualidad que la uniformidad. La sorpresa no sólo se permite: se busca. El sello personal tiene importancia.

Eisner, 2004:206

\section{EL MUSEO, UN ESPACIO PARA COMPARTIR, UN ÁMBITO DE EN- CUENTRO CON UNO MISMO Y CON LOS OTROS, DE INTERACCIÓN ENTRE CONTEXTO, PERSONAS Y MATERIALES}

El proceso de creación artística, de generación de ideas, uso de los materiales y técnicas y la interacción con los otros permite que el taller se convierta en un lugar de encuentro entre numerosos pensamientos, sensaciones y percepciones que potencian las asociaciones y la creación de nuevos significados y conocimientos. Los usuarios se encuentran inmersos en un ambiente generador de ideas, las suyas propias y las de los otros. Algunos copian ideas de sus compañeros o siguen sus sugerencias y las de los educadores (se ha de intentar la no anticipación a los deseos de estas personas). Se potencia la copia porque puede dar lugar a enlazar su contenido con pensamientos propios que a su vez den lugar a nuevas y distintas creaciones; sin esa influencia

\footnotetext{
${ }^{20}$ Como ocurrió durante la realización de la maqueta de la ciudad ideal: las cajas de cartón eran edificios, bolas de papel de seda verde eran árboles, etc.
} 
inicial en algunos casos quizá no se conseguirían resultados que generen satisfacción y confianza en las propias posibilidades.

Se consigue durante la actividad de taller la dinámica de un espacio para la creación artística con diversidad de materiales que permiten experimentar, descubrir, investigar, crear, etc., en el que la elección y la toma de decisiones es constante. Todos los materiales plásticos están al alcance de los participantes y permiten la entrada en la dinámica de un taller de creación por el que se mueven con seguridad y tranquilidad, de manera independiente y autónoma. Dejan de aparecer conductas disruptivas, ya que autorregulan sus comportamientos y autogestionan su actividad.

El trabajar en un proyecto común, implica un cambio de rol de la persona creadora individual y pone de relieve la «autoría múltiple». Significa que cada persona ha de elegir una parte a desarrollar de manera individual o colaborar con otros. Esta elección requiere un gran compromiso por parte de los usuarios, cada uno de ellos tiene un papel diferente en el proyecto común, es responsable de una parte para la construcción del todo. En este tipo de trabajos cooperativos se manifiesta confianza en ellos y en sus capacidades. Los participantes se mueven por el taller tranquilamente buscando materiales, instrumentos para trabajar, etc.; cada uno tiene un objetivo individual que ha decidido para una finalidad común.

Como nos dicen las artistas Christine e Irene Hohenbüchler (en Grosenick, 2001) esta dinámica de trabajo cooperativo, más que nunca, se convierte en un proceso creativo en el que la fuerza de cada miembro intensifica el trabajo y conduce a un resultado imprevisible que satisface a cada individuo.

Una dinámica de grupo intensificadora conduce a un resultado imprevisible. Christine and Irene Hohenbüchler ${ }^{21}$, en Grosenick, 2001: 24

En definitiva hay una retroacción constante entre contexto, personas y materiales en el proceso de creación artística por su propia naturaleza: el sujeto manipula materiales con unas técnicas en un contexto de acuerdo con sus propósitos, en un proceso que varía según cambios en el contexto, los materiales, las técnicas y los propósitos (se producen nuevas asociaciones, se plantean nuevos objetivos por ejemplo).

\section{EL MUSEO, UN ESPACIO GENERADOR DE PROPUESTAS PARA LA PRÁCTICA DEL ARTE Y UN LUGAR DE CREACIÓN DE PENSAMIENTO Y DE EJECUCIÓN: DE PENSAR Y DE HACER}

El arte, por la variedad de contenidos y significados que presenta y por las diversas maneras como puede ser representado, nos ofrece numerosas alternativas de análisis

\footnotetext{
${ }^{21}$ Christine and Irene Hohenbüchler (1964, Viena, Austria) artistas visuales y plásticas. Son gemelas y trabajan juntas desde 1988. Exponen sus pinturas, esculturas e instalaciones tanto en reconocidos espacios de exposición como en lugares donde las presentaciones artísticas son poco frecuentes como cárceles y hospitales psiquiátricos.
} 
y de creación: podemos investigar sobre el contexto histórico y social del artista o del momento representado, explorar la obra desde un punto de vista formal, estudiar los materiales utilizados, analizar y experimentar las técnicas, etc. A partir de las obras de arte, podemos crear numerosas situaciones de enseñanza-aprendizaje para todas las personas.

A través de la observación-contemplación y estudio de las obras de arte, los participantes descubren nuevas formas de vida, de entenderla, nuevas formas de expresión y de creación. El solo hecho de observar las obras despierta una serie de emociones y sentimientos únicos: la emoción de la sorpresa, las ganas de conocer más sobre las obras, los artistas, lo representado, etc. las obras de arte emocionan y estimulan el deseo de saber más.

El estudio del arte permite la comprensión del mundo, de la actividad y del pensamiento humano de una determinada época, y de sus propias creaciones artísticas, de su mundo interior.

Las obras de arte funcionan como referentes visuales para el proceso de creación artística. No se plantean como modelos a reproducir y/o copiar, lo cual iría en contra del proceso de creación artística y de la libre expresión que se pretende, sino como modelos que pueden servir de inspiración a los participantes para sus propias creaciones, para mostrar algunas de las posibilidades que tienen ante sí. Ante un papel en blanco, poseer referentes visuales da seguridad a la persona creadora (que también tiene la posibilidad de copiar). Según vaya aumentando la seguridad personal se irá distanciando de estos referentes a la hora de realizar creaciones artísticas totalmente libres y creativas, en las que afloran pensamientos, intereses, deseos y emociones del creador.

La improvisación, gracias a la asociación de ideas y pensamientos que aparece en el proceso de creación artística, provoca cambios importantes en las conductas adaptativas de las personas con necesidades específicas de apoyos (destrezas cognitivas y de comunicación/académicas, destrezas de competencia social y destrezas prácticas). Pone en juego habilidades matemáticas y lingüísticas que son requeridas al hablar de las características de los materiales, al representar simbólicamente, al utilizar conceptos básicos matemáticos: arriba, debajo, entre, etc. las formas geométricas, etc. Todo ello les permite progresar en numerosas competencias, convirtiéndose en un ejemplo claro de educación a través de las artes como propugna la UNESCO ${ }^{22}$.

${ }^{22}$ UNESCO (2006) "Conferencia Mundial sobre la Educación Artística: construir capacidades creativas para el siglo XXI. Hoja de ruta para la Educación Artística”.

http://portal.unesco.org/culture/es/ev.php-

URL_ID=39546\&URL_DO=DO_TOPIC\&URL_SECTION=201.html

[Ưltima consulta el $\overline{1}$ de diciembre de 2010]

UNESCO (2010) "La Agenda de Seúl: Objetivos para el desarrollo de la educación artística". http://portal.unesco.org/culture/es/ev.php-

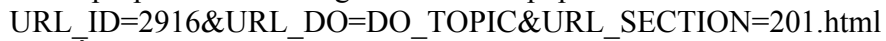

[Ưltima consulta el 1 de diciembre de 2010] 
Estas personas no encuentran la seguridad en las pautas establecidas sino que la encuentran en la adquisición de habilidades adaptativas. El éxito en improvisaciones propias, con pensamiento causal y consecuencial, les permite fortalecer el pensamiento divergente que impulsa la actitud creativa en la persona.

Los participantes tienen la posibilidad de comprobar cuáles son sus capacidades, qué son capaces de hacer. Por otra parte la interacción entre todos los participantes va mejorando, a medida que pasan las sesiones. En todo momento se intenta que las emociones aparezcan, no se reprimen; que los participantes se hagan conscientes de su estado emocional para aumentar el conocimiento sobre ellos mismos. Por ello podemos señalar el progreso en las inteligencias intra e interpersonal señaladas por $\operatorname{Gardner}^{23}$ (1995).

Necesitan que el adulto que les acompaña les ceda el tiempo necesario para pensar, construir, decidir, realizar acciones, elegir, etc. en todas las actividades de la vida. De esta manera se estarán potenciando la autodeterminación de la persona, hay que ceder el tiempo, sin anticipaciones, mostrando confianza en las posibilidades y capacidades de estas personas.

\section{EL MUSEO, UN ESPACIO PARA EXHIBIR LOS PROCESOS DE CREA- CIÓN Y LOS RESULTADOS}

Las experiencias anteriores son un camino de reflexión, expresión y comunicación compartido que culmina en la exposición del objeto creado junto con el análisis último realizado por todos los participantes.

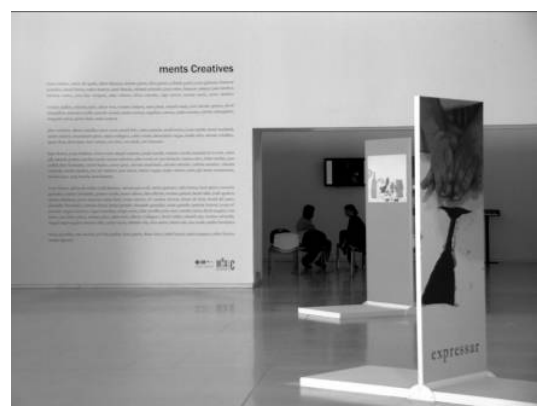

Fig. 5. Exposición ments Creatives, 2007. Exhibición del proceso y de los resultados del proyecto Natures Mortes a la Sala Oval del MNAC

La exposición de las obras es el elemento de cierre de todo proceso de creación artística. Mostrar la obra a los demás hace que el resultado del proceso de creación artística -considerado hasta ese momento expresión personal- pase a ser comunicación fuera de los límites físicos del taller; la obra se exhibe para que los demás sean los receptores, la perciban y se emocionen con ella.

Transformar lo privado en algo público es un proceso fundamental tanto en el Arte como en la ciencia. Ayudar a los jóvenes a aprender a efectuar esta

\footnotetext{
23 (1995). Inteligencias múltiples. La teoría en la práctica. Barcelona, Paidós.
} 
transformación es otro de los objetivos más importantes de la educación. Es un proceso que depende inicialmente de la capacidad de experimentar las cualidades del entorno, cualidades que alimentan nuestra vida conceptual y que luego usamos para alimentar nuestra imaginación.

Eisner, 2004: 20

\section{CONCLUSIÓN}

A lo largo de todo el texto anterior hemos utilizado como hilo conductor la descripción y análisis de varias intervenciones educativas en el ámbito museístico con personas con necesidad de soportes específicos. Su investigación nos aporta las características que han de tener los proyectos específicos e inclusivos para este tipo de colectivos, y también, la transformación que muchos de los museos de arte están consiguiendo y sus potencialidades.

El museo se convierte en un espacio de adquisición de contenidos de educación artística y de todos aquellos que tienen que ver con una educación amplia que contempla todas aquellas habilidades que hacen de la persona un ser único, social y principal protagonista en la creación de su propio conocimiento; en un espacio de contemplación y observación, de diálogo intenso entre todos los protagonistas, entre ellos, las obras de arte y las producciones de los participantes; en un espacio en el que investigar, experimentar y expresar intereses, deseos y emociones.

El museo de arte aparece como un expositor de que es posible el acceso al arte y a la cultura de todo tipo de colectivos. Muestra cómo es posible llevar a cabo proyectos específicos e inclusivos en los que participan personas con diversidad funcional.

El museo se convierte en un lugar en el que conviven, crean, investigan, dialogan, crean, etc. personas de características bien diversas y que son capaces de originar conocimiento: de ser y de estar. Los museos con sus programas específicos e inclusivos son modelos de una sociedad equitativa, respetuosa y tolerante, que acepta y potencia esa diversidad social que nos enriquece a todos.

Concluimos con algunas notas de espectadores en el libro de la exposición del último proyecto Retrats:

Un proyecto encantador, es muy agradable ver todas las capacidades que tienen y que se pueden estimular en lugares que hasta ahora eran vetados para ellos. Corage para seguir haciendo proyectos como éste.

Felicidades por la exposición y por la idea. Me han encantado las historias sobre los cuadros y las versiones plásticas de estos artistas.

¡Muchas gracias! Our Museum of Modern Art (MOMA) could copy your wonderful idea! 


\section{REFERENCIAS BIBLIOGRÁFICAS}

EISNER, E. (2004) El arte y la creación de la mente. Barcelona, Paidós

EISNER, E. (2005) Educar la visión artística. Barcelona, Paidós. (1ª edición, 1972)

EISNER, E. (2008) «El museo como lugar para la educación». En Las actas del I Congreso Internacional. Los museos en la educación. La formación de los educadores. (pp. 13-21) Madrid, Museo Thyssen-Bornemisza

ESSERS, V. (2002) Matisse. Köln: Ed.Taschen

GROSENICK, U. (ed.) (2001) Mujeres artistas de los siglos XX y XXI. Colonia, Taschen

JOLLIEN, A. (2001) Elogio de la debilidad. Barcelona, RBA Libros S.A.

MORÓN, M. (2008) “L'art com a potenciador de coneixements i d'experiències en persones amb necessitat de suports específics “. Revista Guix. Núm. 350. P. 41 46. Desembre 2008.

MORÓN, M. (2010). Color: Un taller inclusivo al MNAC. A les actes de les 16 jornades DEAC. Museos, espacios para compartir. IVAM Valencia. Format digital. P. 187-195. http://www.ivam.es/catalogopdf/0578/\#/188/ [Última consulta el 1 de septiembre de 2011]

MORÓN, M. (2011) La creación artística en la educación de las personas con discapacidad intelectual. La autodeterminación. Tesis doctoral. Directoras: Isabel Gómez Alemany i Marián López-Fernández Cao. Facultat de Formació del Professorat. UB. https://www.educacion.es/teseo/mostrarRef.do?ref=927870 [Última consulta el 1 de septiembre de 2011]

SCHALOCK, R. (1999) "Hacia una nueva concepción de la discapacidad". Siglo Cero. Revista española sobre Discapacidad Intelectual. Madrid: FEAPS. Vol. 30 (1), 1, 5-20

SCHALOCK, R. (2001) "Conducta adaptativa, competencia personal y calidad de vida". En Verdugo, A. y Borja, F. (coord.). Apoyos, autodeterminación y calidad de vida. IV Jornadas científicas de investigación sobre personas con discapacidad. (pp. 83-104). Salamanca, Amaru Ediciones 